Article

\title{
Electrospun Combination of Peppermint Oil and Copper Sulphate with Conducive Physico-Chemical properties for Wound Dressing Applications
}

\author{
Saravana Kumar Jaganathan ${ }^{1,2,3, *}$, Mohan Prasath Mani ${ }^{4}$ and Ahmad Zahran Md Khudzari ${ }^{3}$ \\ 1 Department for Management of Science and Technology Development, Ton Duc Thang University, \\ Ho Chi Minh City, Vietnam \\ 2 Faculty of Applied Sciences, Ton Duc Thang University, Ho Chi Minh City, Vietnam \\ 3 IJNUTM Cardiovascular Engineering center, School of Biomedical Engineering and Health Sciences, \\ Faculty of Engineering, Universiti Teknologi Malaysia, Skudai 81310, Malaysia; zahran.kl@utm.my \\ 4 School of Biomedical Engineering and Health Sciences, Faculty of Engineering, Universiti Teknologi \\ Malaysia, Skudai 81310, Malaysia; mohanprasathutm@gmail.com \\ * Correspondence: saravana@tdtu.edu.vn; Tel.: +84-8-37-755-037
}

Received: 27 February 2019; Accepted: 20 March 2019; Published: 1 April 2019

\begin{abstract}
The ultimate goal in tissue engineering is to fabricate a scaffold which could mimic the native tissue structure. In this work, the physicochemical and biocompatibility properties of electrospun composites based on polyurethane (PU) with added pepper mint (PM) oil and copper sulphate $\left(\mathrm{CuSO}_{4}\right)$ were investigated. Field Emission Electron microscope (FESEM) study depicted the increase in mean fiber diameter for $\mathrm{PU} / \mathrm{PM}$ and decrease in fiber diameter for $\mathrm{PU} / \mathrm{PM} / \mathrm{CuSO}$ compared to the pristine PU. Fourier transform infrared spectroscopy (FTIR) analysis revealed the formation of a hydrogen bond for the fabricated composites as identified by an alteration in PU peak intensity. Contact angle analysis presented the hydrophobic nature of pristine PU and PU/PM while the $\mathrm{PU} / \mathrm{PM} / \mathrm{CuSO}_{4}$ showed hydrophilic behavior. Atomic force microscopy (AFM) analysis revealed the increase in the surface roughness for the $\mathrm{PU} / \mathrm{PM}$ while $\mathrm{PU} / \mathrm{PM} / \mathrm{CuSO}_{4}$ showed a decrease in surface roughness compared to the pristine PU. Blood compatibility studies showed improved blood clotting time and less toxic behavior for the developed composites than the pristine PU. Finally, the cell viability of the fabricated composite was higher than the pristine PU as indicated in the MTS assay. Hence, the fabricated wound dressing composite based on PU with added PM and $\mathrm{CuSO}_{4}$ rendered a better physicochemical and biocompatible nature, making it suitable for wound healing applications.
\end{abstract}

Keywords: polyurethane; $\mathrm{PM} / \mathrm{CuSO}_{4}$; physico-chemical properties; biocompatibility; wound healing applications

\section{Introduction}

The largest organ in the human body is skin which plays a critical role in homeostasis and inhibits microorganism invasion. A wound is an injury to the skin when the skin tissue gets damaged. An injury is caused due to trauma, burns, or other by other factors like foot ulcers due to diabetes. Once the skin gets affected, it should be treated immediately, otherwise it can cause acute pain, serious infections, and also wound burden [1]. The treatment for the damaged skin involves the use of wound dressing which acts as a skin barrier and aids wound healing [2]. An Rideal wound dressing should be biocompatible, non-allergic, providing a moist environment, facilitates gas exchange, adsorbs exudates, and reduces pain and risk of infection [3]. Further, it should display good biocompatibility 
and also resemble the native ECM structure for supporting new tissue formation [1,4]. Now-a-days, the nanofibrous scaffold was reported to be widespread in the tissue engineering applications.

Nanofibers were fabricated using various processing techniques such as emulsion freeze drying, self-assembly, and phase separation [1]. The nanofibers fabricated using the above techniques were used in several applications such as energy applications [5], treatment of water and environment [6], healthcare, and biomedical engineering [7,8]. However, the nanofibers produced using these techniques does not meet the requirements of the ideal wound dressing membrane because of their large diameters and low porosity [9]. In addition, the nanofibers based on the electrospinning technique were widely used in biomedical applications because of their large surface area to volume ratios and porous structure [10]. The small interconnected pores of the electrospun membranes do not help suitable cellular response and tissue ingrowth. However, the pore size can be tailor made by optimizing or tuning the electrospinning parameters such as voltage, flow rate and collector distance [11]. Tang et al. reported that the increase in flow rate resulted in an increase in fiber diameter [12]. Similarly, Zhang et al observed that the low voltage favors the smaller fiber diameter while the high voltage results in broader fiber diameter [13]. Further, Yuan et al. reported that the thin fiber was formed for a larger collector distance and vice versa [14]. Tarus et al reported that the solvent with lower surface tension causes smoother fibers and fibers will be higher for other solvents with higher surface tension [15]. Further, electrospinning is a cost effective, facile, and well established technique used to fabricate nanofibers from both natural and synthetic polymers [16]. Some of the natural polymers used in the wound dressing were chitosan, collagen, alginate, gelatin, chitin, and silk fibroin. While the synthetic polymers used were poly(vinyl alcohol), poly(lactic acid), polycaprolactone (PCL), and poly(ethylene oxide) [1]. In this study, the Tecoflex EG $80 \mathrm{~A}$ was used to fabricate the wound dressing scaffold. It belongs to the family of aliphatic polyether polyurethanes. It possesses good mechanical and ultraviolet (UV) stability [17]. For the past few decades, it was widely used in biomedical applications because of its biocompatible and biodegradable behaviour, oxidative and thermal stability $[18,19]$.

An ideal scaffold for wound dressing must possess improved biocompatibility for influencing the fibroblast adhesion and also have antimicrobial activity to inhibit the microbes penetration. Unnithan et al. studied electrospun polyurethane ( $\mathrm{Mw}=110,000$, Medical grade) scaffold with added emu oil fibers. It was shown that the emu oil incorporated PU scaffolds showed enhanced adhesion of fibroblast cells compared to the pristine polyurethane [20]. In another study, Jaganathan et al. fabricated polyurethane (Tecoflex EG 80A) scaffold added with grape seed oil, honey, and propolis. It was reported that the addition of grape seed improved the fibroblast adhesion compared to the pristine PU [21]. Hence these studies have proved that the addition of essential oil influenced the fibroblast adhesion and proliferation. Hence, these types of studies motivated us to use pepper mint (PM) oil for wound dressing applications. Mentha piperita L., known as peppermint oil, is a medicinal plant belongs to the Lamiaceae family [22]. It is widely found in temperate areas of the world, mainly in North America, Europe, and North Africa. Peppermint is composed of 29-48\% menthol, about $20-31 \%$ menthone, $6.8 \%$ menthofuran, and 3-10\% menthyl acetate. Other bioactive compounds include flavonoids, caffeic acid, polyphenols, tocopherols, carotenes, tannins, betaine, and choline [23-25]. Owing to their various bioactive constituents, it was used in food, cosmetic, and clinical applications. It has been utilized for treating colds, cancers, cramps, indigestion, sore throat, nausea, and toothaches. The polyphenolic constituents of PM oil might stimulate the immune system and help in preventing colds and similar viral infections [26]. These constituents also help in protecting the cells from free radicals and exert anticancer activity [27]. Further, it has been reported to possess some biomedical activities of an antibacterial, antiviral, and antioxidant nature [22]. Furthermore for wound dressing applications, it must impart or enhance the antimicrobial activity. Hence, it is necessary to add some efficient antibacterial agents into the fabricated scaffolds. In this research the copper sulphate $\left(\mathrm{CuSO}_{4}\right)$ is selected. Literature reported that silver, copper, and zinc are less toxic with excellent antimicrobial activity compared to the other metallic particles. In addition to promising antimicrobial activity, copper also plays a vital role in aiding the various physiological and metabolic processes like promoting 
endothelial cells growth, accelerating angiogenesis, and equilibrium of extracellular skin proteins [28]. The aim of this research is to develop and characterize a novel wound dressing scaffold based on polyurethane added with $\mathrm{PM}$ oil and $\mathrm{CuSO}_{4}$.

\section{Experimental}

\subsection{Materials}

PU (Medical grade Tecoflex EG 80A) was supplied by Lubrizol, Wickliffe, OH, USA. PM oil was purchased from AEON, Johor, Malaysia. Copper sulphate $\left(\mathrm{CuSO}_{4.5} \mathrm{H}_{2} \mathrm{O}\right)$ was supplied by Sigma-Aldrich, Gillingham, UK. The solvent for PU is Dimethylformamide (DMF) which was obtained from Merck, Burlington, NJ, USA. The reagents utilized in clotting study was obtained from Diagnostic Enterprise, Thiruvananthapuram, India.

\subsection{Preparation of $\mathrm{PU}$, Composite Solution and Electrospinning process}

The homogeneous solution of PU, PM oil, and $\mathrm{CuSO}_{4}$ was prepared at $9 \mathrm{wt} \%, 4 \mathrm{v} / \mathrm{v} \%$ and $4 \mathrm{wt} \%$ respectively. To make $9 \mathrm{wt} \%$ of PU solution, $0.315 \mathrm{~g}$ of PU pellets was added to $3.5 \mathrm{~mL}$ of DMF and stirred for $12 \mathrm{~h}$ at room temperature. Similarly, $80 \mu \mathrm{L}$ of PM oil was added to $2 \mathrm{~mL}$ of DMF and stirred for $1 \mathrm{hr}$ maximum to make $4 \mathrm{v} / \mathrm{v} \% \mathrm{PM}$ solution. Further, $4 \mathrm{wt} \%$ of $\mathrm{CuSO}_{4}$ solution was done by

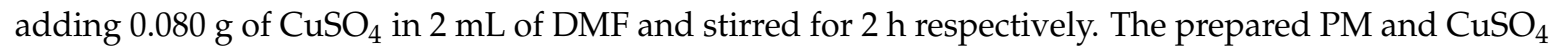
homogeneous solution were added to the PU solution at an 8:1 v/v \% for PU/PM and 8:0.5:0.5 v/v \% for $\mathrm{PU} / \mathrm{PM} / \mathrm{CuSO}_{4}$. In this research, the electrospinning technique was used to develop a fibrous scaffold from the prepared homogenous solution. They were electrospun at a voltage of $11 \mathrm{kV}$, a flow rate of $0.3 \mathrm{ml} / \mathrm{h}$, and a distance of $20 \mathrm{~cm}$ respectively [21]. The parameters were kept constant for all solutions for even comparison. The attained fibers were collected using aluminum foil and vacuum dried to remove any residues.

\subsection{Morphological and Structural Characterization}

Field emission scanning electron microscopy (FESEM) unit (Hitachi SU8020, Tokyo, Japan) was employed to analyze the morphology of as-spun membranes. The samples were coated with gold and imaged at different magnifications. The fiber diameter was measured using Image J software by choosing 30 locations randomly from the captured image. The wettability of the fibrous membranes was determined through static video contact angle equipment (AST products, Inc., Billerica, MA, USA). Sample with a size of $1 \times 1 \mathrm{~cm}^{2}$ was placed on the measuring surface and deposited with a water droplet $(0.5 \mu \mathrm{L})$. The image of the water droplet was captured within a few seconds via video camera. The computer integrated software measure the manual contact angle and the experiment was repeated for three trials. For IR analysis, the electrospun samples were measured over wavelengths between 600 and $4000 \mathrm{~cm}^{-1}$ at $4 \mathrm{~cm}^{-1}$ resolution in Nicolet iS 5 , Thermo Fischer Scientific, Waltham, MA, USA. The ATR crystal employed is Zinc Selenium (ZnSe). The thermal stability was measured in thermogravimetric analysis (TGA) unit (PerkinElmer, Waltham, MA, USA) by heating a small piece of electrospun membrane ( $3 \mathrm{mg}$ ) between 30-1000 degree celcius under the nitrogen atmosphere. The remaining weight residue was measured at each temperature point and the obtained values were exported in an excel sheet. Finally, the surface morphology was determined using atomic force microscopy (AFM) unit (NanoWizard $®$, JPK Instruments, Berlin, Germany) under normal atmosphere by scanning the electrospun membrane in size of $20 \mathrm{um} \times 20 \mu \mathrm{m}$ area and images in 256 resolution were obtained. Ra was calculated at three different locations using the integrated JPKSPM software.

\subsection{Mechanical Characterization}

Mechanical properties of the electrospun PU, PU/PM, and PU/PM/CuSO $\mathrm{Composite}_{4}$ was measured by universal testing equipment (Gotech Testing Machines, AI-3000). The samples with 
a size of $40 \mathrm{~mm} \times 15 \mathrm{~mm}$ was clamped in the testing machine with a gauge length of $20 \mathrm{~mm}$. The test was performed at a velocity of $10 \mathrm{~mm} / \mathrm{min}$ with a load cell of $500 \mathrm{~N}$ at room temperature. The computer integrated software displays the stress-strain curve from which the average tensile strength at maximum stress was measured.

\subsection{Coagulation Assays}

\subsubsection{Activated Partial Thromboplastin Time (APTT) and Prothrombin Time (PT) Assay}

$\mathrm{PU}, \mathrm{PU} / \mathrm{PM}$, and $\mathrm{PU} / \mathrm{PM} / \mathrm{CuSO}_{4}$ scaffolds were cut into a size of $1 \times 1 \mathrm{~cm}^{2}$ and incubated with $50 \mu$ l of platelet poor plasma (PPP) for $1 \mathrm{~min}$ at $37^{\circ} \mathrm{C}$. Afterwards, $50 \mu \mathrm{l}$ of rabbit brain cephaloplastin reagent was further added and incubated for $2 \mathrm{~min}$ at $37^{\circ} \mathrm{C}$. Finally, the blood clot was initiated by adding $50 \mu \mathrm{L}$ of $\mathrm{CaCl}_{2}$ and the formation of the clot was investigated with a sterile steel needle. The time taken for the blood clot was noted using a chronometer. Similarly for PT assay, the samples size of $1 \times 1 \mathrm{~cm}^{2}$ was incubated with $50 \mu \mathrm{l}$ of obtained PPP for $1 \mathrm{~min}$ at $37^{\circ} \mathrm{C}$. After, it was added with $50 \mu \mathrm{L}$ of $\mathrm{NaCl}$-thromboplastin reagent (Factor III) which initiate the blood clot. The time taken for the clot formation was measured by chronometer.

\subsubsection{Hemolysis Assay}

Hemolysis assay was done to investigate the toxicity of electrospun membranes with red blood cells. Initially, the samples $\left(1 \times 1 \mathrm{~cm}^{2}\right)$ were soaked in $0.9 \% \mathrm{w} / \mathrm{v}$ of physiological saline at $37^{\circ} \mathrm{C}$ for $30 \mathrm{~min}$. Next, they were added with a mixture of aliquots of citrated blood and diluted saline (4:5) for $1 \mathrm{~h}$ at $37^{\circ} \mathrm{C}$. After, the samples were retrieved and the mixture was centrifuged at $3000 \mathrm{rpm}$ for $15 \mathrm{~min}$. Finally, the supernatant was aspirated and the optical density was recorded at $542 \mathrm{~nm}$ which depicts the release of haemoglobin. The percentage of hemolysis or hemolytic index was calculated using the formula [21]:

$$
\text { Hemolysis ratio }(\mathrm{HR})=(\mathrm{TS}-\mathrm{NC}) /(\mathrm{PC}-\mathrm{NC}) \times 100
$$

where TS, NC, and PC are measured absorbance values of the test sample, negative control, and positive control at $542 \mathrm{~nm}$, respectively.

\subsection{Characterization of In Vitro Biocompatibility}

HDF (Human Skin Fibroblast Cells 1184, ECACC, UK, primary cells obtained from the dermis of the skin) were cultured in DMEM medium supplied with $10 \%$ fetal bovine serum and incubated at $37{ }^{\circ} \mathrm{C}$ with $5 \% \mathrm{CO}_{2}$. The medium was replaced every 3 days. The electrospun membranes with dimensions of $0.5 \mathrm{~cm} \times 0.5 \mathrm{~cm}$ were cut and placed in the 96 well plates. Once the cells reached $80 \%$ confluence, they were seeded onto the scaffolds at a density of $10 \times 10^{3}$ cells $/ \mathrm{cm}^{2}$. MTS assay was used to determine the cell viability of the cells after 5 days culturing. After 5 days of culture, the medium in which cell is grown on the electrospun membranes was added with $20 \%$ of MTS solution and incubated for $4 \mathrm{~h}$. After $4 \mathrm{hr}$, the absorbance was measured at a wavelength of $490 \mathrm{~nm}$ using a spectrophotometric plate reader.

\subsection{Statistical Analysis}

One way ANOVA followed by Dunnett post hoc test was performed for experiments results with three trails to determine statistical significance. The analyzed data were expressed as mean \pm SD for three trials. A representative of three images was presented for qualitative experiments. 


\section{Result and discussion}

\subsection{FESEM Investigation}

FESEM images of the prepared electrospun fibrous mats are shown in Figure 1. All the as-spun nanofibrous scaffolds showed a non-woven structure with smooth and beadless morphology. The average fiber size for pure PU was found to be $915 \pm 137 \mathrm{~nm}$, while the PU incorporated with PM and PM/ CuSO4 exhibited fiber sizes of $997 \pm 134 \mathrm{~nm}$ and $359 \pm 166 \mathrm{~nm}$, respectively (mean differences were significant compared with pure PU $(\mathrm{p}<0.05))$. Hence, the addition of PM increased the fiber diameter of the pristine PU, while adding $\mathrm{CuSO}_{4}$ resulted in a decrease in fiber diameter. The alteration in fiber diameter morphology was due to a change in solution parameters while adding $\mathrm{PM}_{\text {and }} \mathrm{CuSO}_{4}$ into the polyurethane matrix. The increase in fiber diameter of PU adding PM oil was due to the interaction of PM oil bioactive constituents with the PU molecules. On the other hand, adding $\mathrm{CuSO}_{4}$ to the $\mathrm{PU} / \mathrm{PM}, \mathrm{CuSO}_{4}$ plays a vital role in reducing the fiber diameter which may be due to the interaction of $\mathrm{PM}$ oil bioactive constituents with the $\mathrm{CuSO}_{4}$ particles. Similar observations were seen in a recent work (Jaganathan et al.), which fabricated polyurethane (Tecoflex EG 80A) scaffold with added copper particles for wound dressing applications. It was found that the addition of copper particles resulted in the reduction of the fiber diameter which correlates with our observation. Further, in their work, the developed composites showed an enhanced proliferation rate of fibroblast cells than the pristine PU [29]. The fiber diameter of the fabricated composites showed a reduced fiber diameter compared to the pristine PU which might be conducive for the wound dressing applications. Further, EDS study was performed to confirm the presence of copper in the polyurethane matrix. From Table 1, it was evident that the polyurethane matrix showed some content of copper $(1.5 \%)$ in addition to the carbon and oxygen content.

(a)

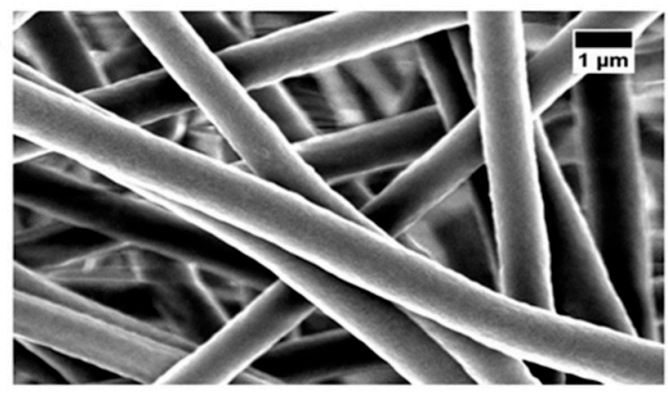

(b)

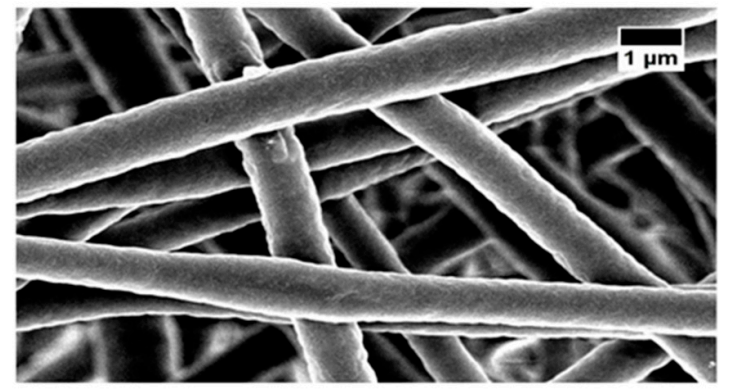

(c)

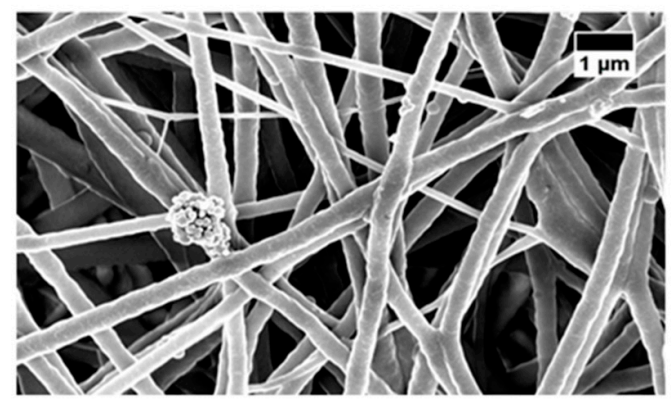

Figure 1. Field Emission Electron microscope (FESEM) images of (a) polyurethane (PU), (b) PU with added pepper mint (PU/PM), and (c) $\mathrm{PU} / \mathrm{PM} / \mathrm{CuSO}_{4}$.

Table 1. EDS table of electrospun membranes.

\begin{tabular}{cccc}
\hline Membrane & Carbon & Oxygen & Copper \\
\hline PU & $78.9 \pm 0.8$ & $21.1 \pm 0.8$ & - \\
\hline PU/PM & $79.1 \pm 1.2$ & $20.9 \pm 1.2$ & - \\
\hline $\mathrm{PU} / \mathrm{PM} / \mathrm{CuSO}$ & & $23 \pm 0.3$ & $1.5 \pm 0.2$ \\
\hline
\end{tabular}




\subsection{FTIR Analysis}

To evaluate the chemical composition of the developed fibrous membrane, FTIR spectra were inspected in wavelength range of $600-4000 \mathrm{~cm}^{-1}$ as indicated in Figure 2. The typical peaks present in the pristine PU are shown in Table 2.

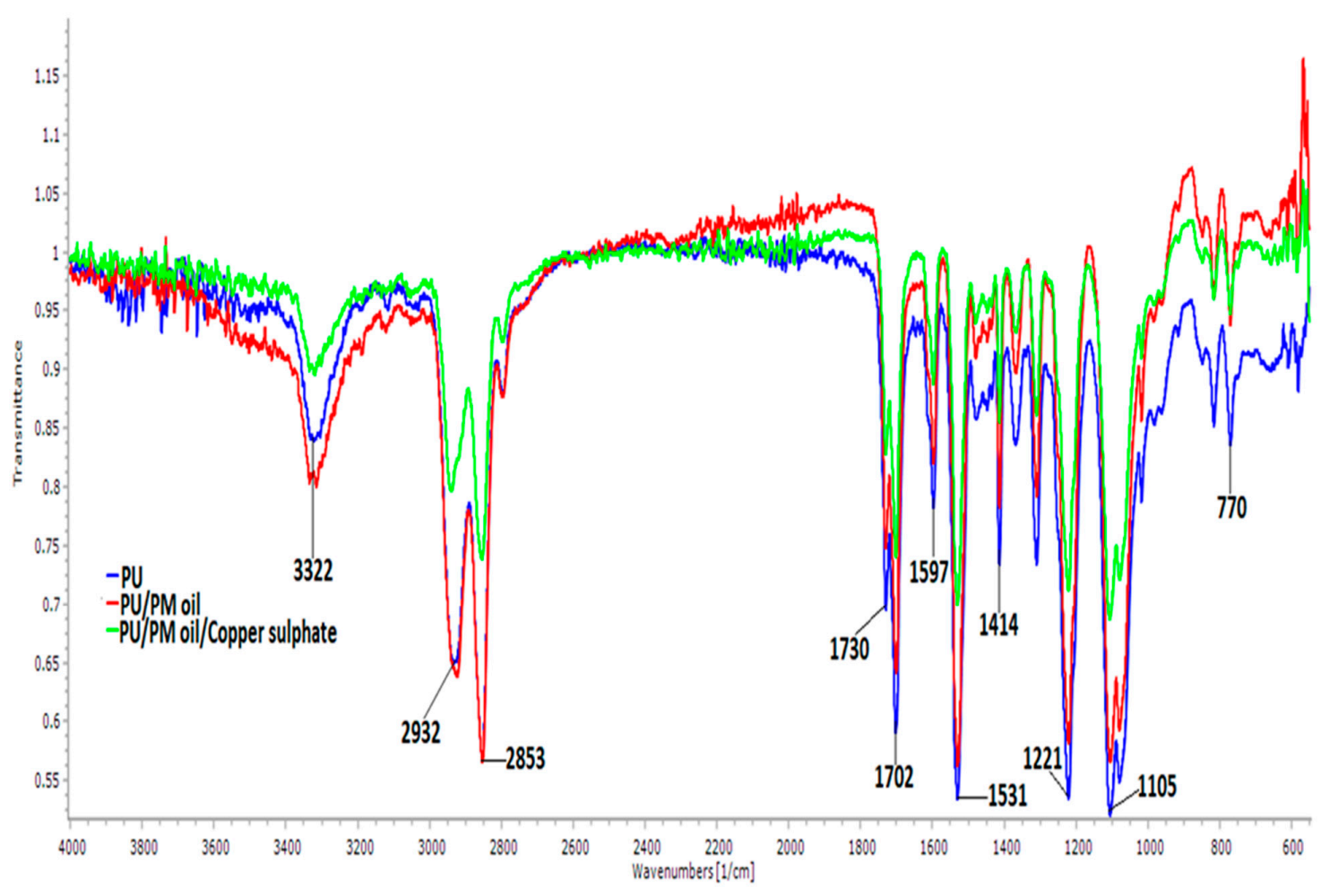

Figure 2. Fourier transform infrared spectroscopy (FTIR) of PU, PU/PM, and PU/PM/CuSO 4 .

Table 2. Functional groups in the electrospun PU membranes.

\begin{tabular}{cc}
\hline Peaks & Band name \\
\hline $3322 \mathrm{~cm}^{-1}$ & $\mathrm{~N}-\mathrm{H}$ \\
\hline 2932 and $2853 \mathrm{~cm}^{-1}$ & $\mathrm{C}-\mathrm{H}$ \\
\hline 1730 and $1702 \mathrm{~cm}^{-1}$ & $\mathrm{C}=\mathrm{O}$ \\
\hline 1531 and $1597 \mathrm{~cm}^{-1}$ & Vibrations of $\mathrm{N}-\mathrm{H}$ \\
\hline $1414 \mathrm{~cm}^{-1}$ & Vibrations of $\mathrm{C}-\mathrm{H}$ \\
\hline 1221,1105, and $770 \mathrm{~cm}^{-1}$ & $\mathrm{C}-\mathrm{O}$ corresponding to the alcohol group \\
\hline
\end{tabular}

The band at $3322 \mathrm{~cm}^{-1}$ indicates the stretching of NH group, peaks at 2932 and $2853 \mathrm{~cm}^{-1}$ represent the asymmetric and symmetric stretching of $\mathrm{CH}$, and twin peaks at 1730 and $1702 \mathrm{~cm}^{-1}$ were attributed to the $\mathrm{CO}$ group. The vibration of the $\mathrm{NH}$ group was observed at 1531 and $1597 \mathrm{~cm}^{-1}$ and for $\mathrm{CH}$ vibrations it was shown at $1414 \mathrm{~cm}^{-1}$. The other sharp peaks at 1220,1078 , and $770 \mathrm{~cm}^{-1}$ indicate the $\mathrm{CO}$ group with respect to alcohol [21]. For composite membranes, it was found that no new peaks were observed but the intensity of PU was altered (increasing for PU/PM and decreasing for $\mathrm{PU} / \mathrm{PM} / \mathrm{CuSO}_{4}$ ) indicating a formation of a stronger hydrogen bond [20]. The hydrogen bond was formed between molecules of $\mathrm{PM}$ and $\mathrm{CuSO}_{4}$ with PU. The hydrogen bond formation was due to the combination of $\mathrm{OH}$ and $\mathrm{CH}$ molecules present in $\mathrm{PM}$ oil with the molecules of the pristine PU. Hence, the FTIR study confirms the existence of $\mathrm{PM}$ and $\mathrm{CuSO}_{4}$ in the polyurethane matrix. 


\subsection{Wettability Measurements}

The contact angle is a measure of the wettability of the developed membranes. The static contact angle (CA) measurements of the pure PU and their composites were presented. The pure PU fibrous membrane showed a contact angle of $106^{\circ} \pm 3^{\circ}$ indicating its hydrophobic behavior. Upon the incorporation of $\mathrm{PM}$ into the polyurethane matrix, the contact angle was increased to $111^{\circ} \pm 2^{\circ}$, indicating higher hydrophobicity than the pristine PU. On another hand, the addition of $\mathrm{CuSO}_{4}$ to the $\mathrm{PU} / \mathrm{PM}$ resulted in the hydrophilic nature showing a contact angle of $82^{\circ} \pm 1^{\circ}$. Hence, the addition of $\mathrm{CuSO}_{4}$ improved the wettability of the polymer matrix. Jaganathan et al. electrospun polyurethane (Tecoflex EG 80A) scaffold incorporated with zinc particles for wound dressing applications. It was reported that the incorporation of zinc particles improved the wettability of the pristine PU which correlates with our observation. The contact of polyurethane was reported to be $100^{\circ} \pm 0.5774^{\circ}$, while polyurethane added with zinc nitrate displayed contact angle of $84^{\circ} \pm 4.041^{\circ}$. Further, the scaffold with improved wettability exhibited enhanced fibroblast cells adhesion than the pristine PU [30]. The addition of $\mathrm{CuSO}_{4}$ improved the wettability of the PU/PM which might be suitable for better fibroblast cell adhesion and proliferation.

\subsection{TGA Analysis}

The thermal properties of electrospun PU, PU/PM, and PU/PM/CuSO 4 are shown in Figure 3. In the case of pristine PU, the initial degradation temperature was observed to be $266{ }^{\circ} \mathrm{C}$, while for electrospun PU/PM the temperature was increased to $286{ }^{\circ} \mathrm{C}$ and for $\mathrm{PU} / \mathrm{PM} / \mathrm{CuSO}_{4}$, it was decreased to $227^{\circ} \mathrm{C}$. Hence, the thermal properties were increased with the addition of PM. However, adding $\mathrm{CuSO}_{4}$ into the polymer matrix decreased its thermal stability. The decrease in the thermal stability was due to the moisture evaporation present in the copper sulphate pentahydrate. Further, DTG was performed for the electrospun membranes as indicated in Figure 4 and their weight loss peaks were listed in Table 3. From the results obtained, the electrospun PU/PM showed only three weight loss peaks compared to the pristine PU showing four weight loss peaks. However, electrospun $\mathrm{PU} / \mathrm{PM} / \mathrm{CuSO} 4$ showed weight loss peaks as that of pristine PU, but their weight loss intensity was decreased. Hence, the reduced weight loss peaks and decrease in weight loss intensity confirms the reduced weigh loss of the fabricated nanocomposites. Moreover, this attribute also confirms the presence of $\mathrm{PM}$ and $\mathrm{CuSO} 4$ in the polyurethane matrix.

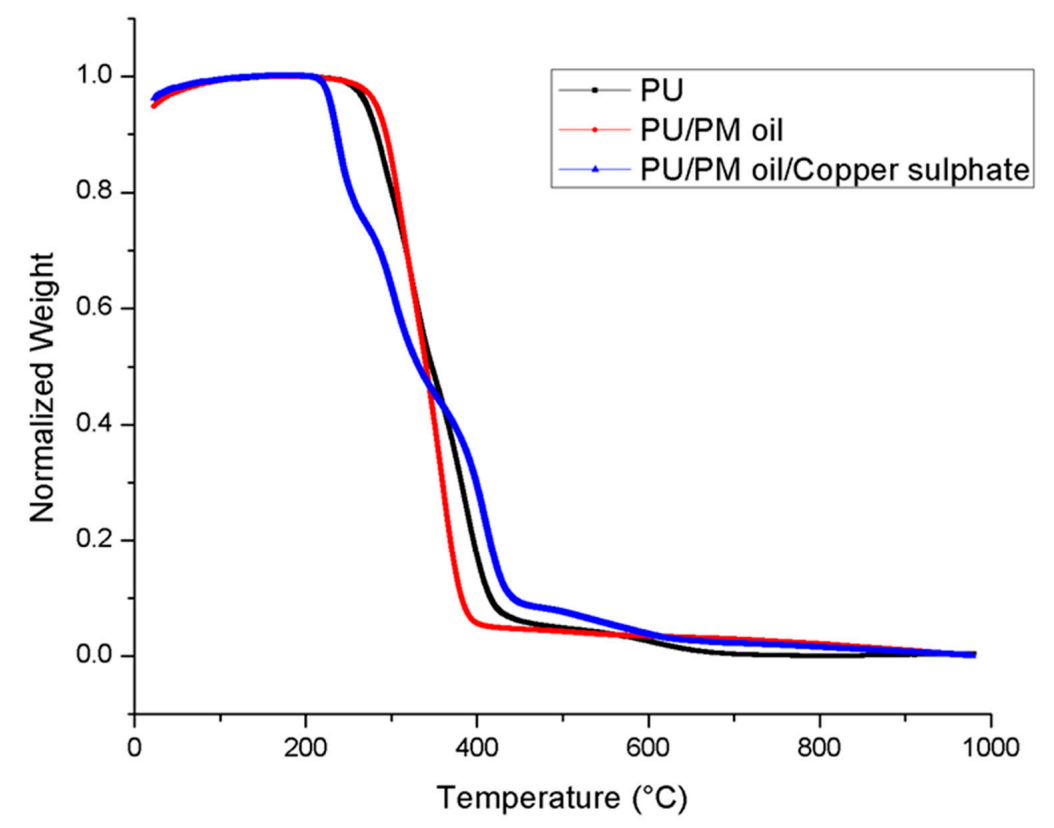

Figure 3. TGA of PU, PU/PM, and PU/PM/CuSO 4. 


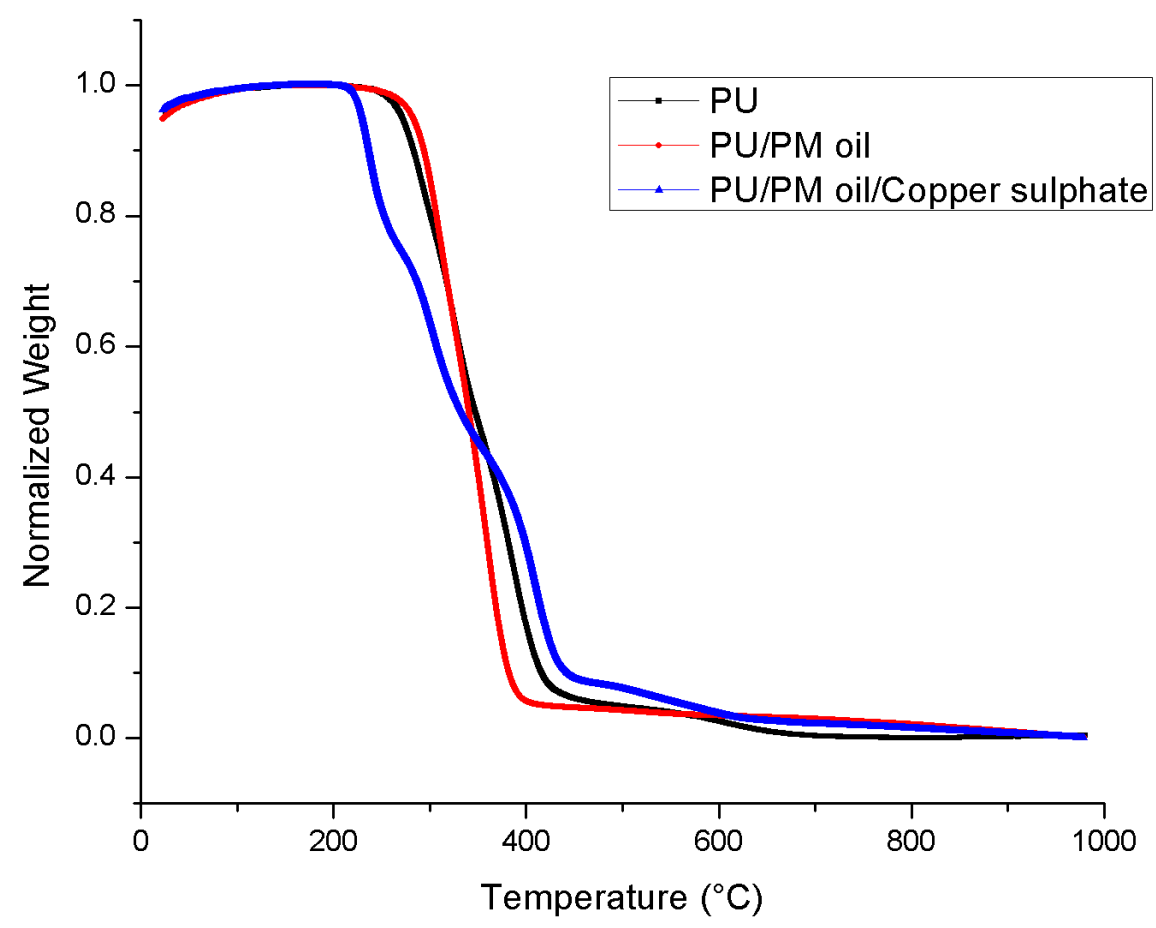

Figure 4. Weight residue of PU, PU/PM, and PU/PM/CuSO

Table 3. Weight loss peaks of electrospun PU, PU/PM, and PU/PM/CuSO 4 .

\begin{tabular}{cccc}
\hline S.NO & PU & PU/PM & PU/PM/CuSO \\
\hline First weight loss & $210{ }^{\circ} \mathrm{C}$ to $302{ }^{\circ} \mathrm{C}$ & $228{ }^{\circ} \mathrm{C}$ to $327^{\circ} \mathrm{C}$ & $206{ }^{\circ} \mathrm{C}$ to $270{ }^{\circ} \mathrm{C}$ \\
\hline Second weight loss & $302{ }^{\circ} \mathrm{C}$ to $353^{\circ} \mathrm{C}$ & $327{ }^{\circ} \mathrm{C}$ to $434^{\circ} \mathrm{C}$ & $270{ }^{\circ} \mathrm{C}$ to $353{ }^{\circ} \mathrm{C}$ \\
\hline Third weight loss & $353{ }^{\circ} \mathrm{C}$ to $494^{\circ} \mathrm{C}$ & - & $353{ }^{\circ} \mathrm{C}$ to $476{ }^{\circ} \mathrm{C}$ \\
\hline Fourth weight loss & $494^{\circ} \mathrm{C}$ to $760{ }^{\circ} \mathrm{C}$ & - & $476{ }^{\circ} \mathrm{C}$ to $664{ }^{\circ} \mathrm{C}$ \\
\hline
\end{tabular}

\subsection{AFM Analysis}

To analyse the effect of $\mathrm{PM}$ and $\mathrm{CuSO}_{4}$ incorporation on the surface roughness of the pristine PU, AFM was performed. The representative 3D images of the fibrous membranes are shown in Figure 5. The average roughness $\left(R_{a}\right)$ of the pristine PU ranged $776 \pm 468 \mathrm{~nm}$, while the PU incorporated with $\mathrm{PM}$ and $\mathrm{PM} / \mathrm{CuSO}_{4}$ have an average roughness of $1039 \pm 198 \mathrm{~nm}$ and $515 \pm 123 \mathrm{~nm}$, respectively. The surface roughness measurements depicted that the fabricated PU/PM composites have rougher surfaces, while PU/PM/CuSO 4 had smoother surfaces compared to the pristine PU. Hyung Hwan Kim et al studied the effect of fiber diameter on surface roughness in electrospun polycaprolactone membrane. It was reported that the average surface roughness was increased with an increase in fiber diameter. Our electrospun PU/PM oil showed a larger fiber diameter which might favor the improvement in the surface roughness. In contrast, the electrospun $\mathrm{PU} / \mathrm{PM} / \mathrm{CuSO}_{4}$ displayed smaller fiber morphology which results in smooth surfaces [31]. Huag et al reported that the fibroblast cells prefer smoother surface to adhere and proliferate [32]. The smooth surface will have a smaller fiber diameter which would be suitable for the fibroblast cells to adhere and grow $[18,31]$. On other hand, Sharifi et al. reported that surface modified polycaprolactone fibrous membrane with increased surface roughness also favors the improved adhesion and growth of fibroblast cells [33]. The influence of surface roughness on the cellular response is still unclear and the various physico-chemical properties of the manufactured composites might have a role in the cell adhesion behavior. To state, the smaller fiber diameter favors the enhanced adhesion of protein which results in large cell attachment and 
proliferation [29]. Further, the adequate porosity also helps in efficient transport of nutrients and waste removal for better cell adhesion and growth [34].

(a)

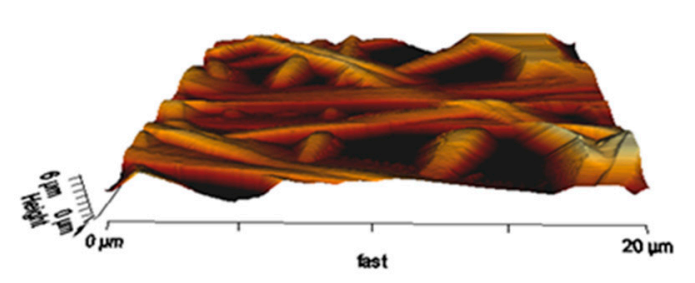

(b)

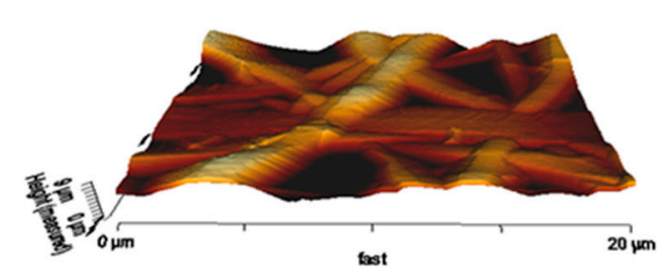

(c)

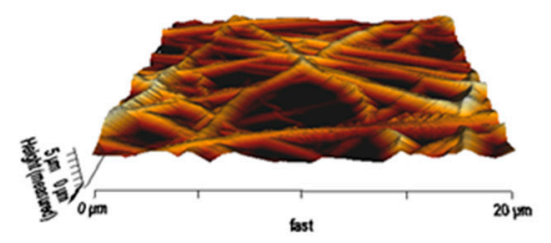

Figure 5. AFM images of (a) PU, (b) PU/PM, and (c) $\mathrm{PU} / \mathrm{PM} / \mathrm{CuSO}_{4}$.

\subsection{Tensile Testing}

Mechanical testing of the electrospun membranes was indicated in Figure 6 and Table 4. The tensile testing clearly indicated that the tensile strength of the pristine PU was enhanced on incorporating PM and $\mathrm{CuSO}_{4}$. PU showed a tensile strength of $6.83 \mathrm{MPa}$ and, on adding $\mathrm{PM}$ and $\mathrm{CuSO}_{4}$, it was increased to $7.04 \mathrm{MPa}$ and $13.60 \mathrm{MPa}$, respectively.

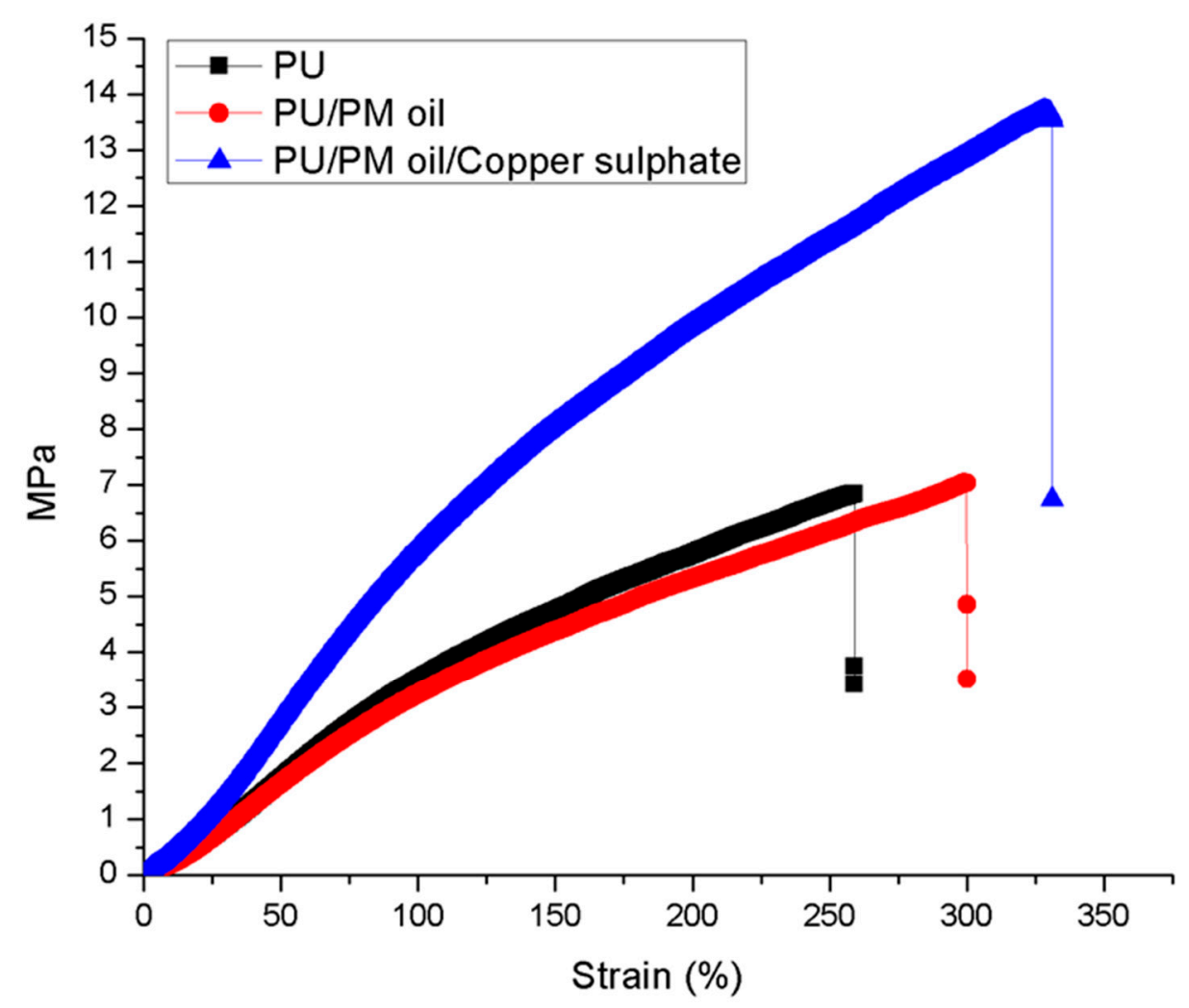

Figure 6. Tensile strength of $\mathrm{PU}, \mathrm{PU} / \mathrm{PM}$, and $\mathrm{PU} / \mathrm{PM} / \mathrm{CuSO}_{4}$. 
Table 4. Mechanical testing values of electrospun membranes.

\begin{tabular}{cccc}
\hline Membrane & $\begin{array}{c}\text { Tensile Strength } \\
\text { MPa }\end{array}$ & $\begin{array}{c}\text { Elastic Modulus } \\
\text { MPa }\end{array}$ & $\begin{array}{c}\text { Elongation at Break } \\
\text { (\%) }\end{array}$ \\
\hline $\mathrm{PU}$ & 6.83 & 3.51 & 259.16 \\
\hline $\mathrm{PU} / \mathrm{PM}$ & 7.04 & 2.95 & 300.10 \\
\hline $\mathrm{PU} / \mathrm{PM} / \mathrm{CuSO}_{4}$ & 13.60 & 5.37 & 331.15 \\
\hline
\end{tabular}

The increase in tensile strength was perhaps due to the homogeneous dispersion of $\mathrm{PM}$ and $\mathrm{CuSO}_{4}$ in the polymer matrix. Unnithan et al. electrospun wound dressing scaffold utilizing polyurethane $(\mathrm{Mw}=110,000)$, Medical grade) and emu oil. It was observed that the polyurethane/emu oil having smaller fiber diameter favored the enhancement of the tensile strength. They concluded that the addition of emu oil might favor the attachment of fibers owing to the hydrogen bond formation between polyurethane and emu oil molecules [20]. As reported earlier, FTIR analysis revealed the hydrogen bond formation in the fabricated composites which might have favored the enhancement of the tensile strength of $\mathrm{PU} / \mathrm{PM} / \mathrm{CuSO}_{4}$. Jaganathan et al. fabricated a wound dressing polyurethane (Tecoflex EG 80A) scaffold added with zinc nitrate. It was found that the zinc nitrate incorporation into the polyurethane exhibited improvement in the mechanical strength which correlates with our findings. They concluded this behavior was because of the smaller fiber diameter (568 $\pm 136.69 \mathrm{~nm})$ of the electrospun composites compared to the polyurethane $(1159 \pm 147.48 \mathrm{~nm})$ [30]. Our fiber diameter reduction was found to be similar to that reported above, which might have resulted in the improvement of the mechanical strength.

\subsection{Blood Compatibility Measurements}

The dressing materials used for wound treatment will frequently come in contact with body fluids such as leakage of plasma and other blood components. If the dressing material does not have hemo-compatible properties, there might be risk of activating an undesired immune response which ultimately result in formation of thrombosis, inflammation, and foreign body reaction. This in turn delays the wound healing process. Hence, an ideal wound dressing should possess better blood compatible properties [35]. Blood clotting time of the electrospun PU, PM, and $\mathrm{PM} / \mathrm{CuSO}_{4}$ was measured using APTT and PT assay. The coagulation assays showed the enhanced anticoagulant nature of the electrospun $\mathrm{PU} / \mathrm{PM}$ and $\mathrm{PU} / \mathrm{PM} / \mathrm{CuSO}_{4}$ compared to the $\mathrm{PU}$ membrane as presented in Figures 7 and 8. The developed PU/PM and $\mathrm{PU} / \mathrm{PM} / \mathrm{CuSO}_{4}$ mat exhibited blood clotting time of $175 \pm 4 \mathrm{~s}$ and $172 \pm 4 \mathrm{~s}$ (mean differences were significant compared with pure PU $(\mathrm{p}<0.05)$ ), while the PU showed blood clotting time of $155 \pm 2 \mathrm{~s}$ as calculated in the APTT assay. Similarly, the developed PU/PM and PU/PM/CuSO 4 mat exhibited blood clotting time of $84 \pm 2 \mathrm{~s}$ and $82 \pm 2 \mathrm{~s}$ (mean differences were significant compared with pure PU $(\mathrm{p}<0.05)$ ), while the PU showed blood clotting time of $70 \pm 1 \mathrm{~s}$ as calculated in the PT assay. The existence of $\mathrm{PM}$ and $\mathrm{CuSO}_{4}$ in the PU matrix delayed the blood clotting time. Further, the hemolytic assay was measured to analyse the electrospun membranes toxicity with red blood cells. The results of hemolytic assay represent that the index value of the electrospun $\mathrm{PU} / \mathrm{PM}$ and $\mathrm{PU} / \mathrm{PM} / \mathrm{CuSO}_{4}$ mat was found to be lower than pristine PU. The pristine PU showed an index value of $2.7 \%$ and for the electrospun PU/PM and $\mathrm{PU} / \mathrm{PM} / \mathrm{CuSO}_{4}$ mat, it was $1.66 \%$ and $1.85 \%$ (mean differences were significant compared with pure PU $(\mathrm{p}<0.05))$ as denoted in Figure 9. The fabricated composite was considered as non-hemolytic because its index value was less than $2 \%$ according to ASTMF756-00(2000) [21]. In blood compatibility assessments, the electrospun PU/PM oil showed prolonging blood clotting time compared to the pure polyurethane. However, there is a slight reduction in the blood clotting time while blending $\mathrm{CuSO}_{4}$ to the PU/PM but the observed blood clotting values were still higher than the pristine PU. According to Huang et al, the blood compatibility is influenced by multiple surface parameters such as wettability, fiber diameter, and surface roughness [36]. Jaganathan et al. electrospun a novel scaffold 
based on polyurethane and mustard oil. They found the improvement in the blood compatibility of the pristine PU with the addition of mustard oil and reported this might be because of an increase in surface roughness [37]. In another study, Ayyar et al. electrospun polyurethane scaffold incorporated with indhulekha oil and determined its anticoagulant nature. It was found that the electrospun $\mathrm{PU} /$ indhulekha oil composite with hydrophobic behavior showed prolonged blood clotting time than the pristine PU [38]. Further, Jaganathan et al. 2017 developed polyurethane scaffold loaded with castor oil using the electrospinning technique. The developed PU/castor oil showed prolonged blood clotting time compared to the pristine PU and this may be due to their smaller fiber diameter [39]. Hence, the addition of PM and CuSO4 into the PU matrix caused reduced fiber diameter morphology (PU/PM/CuSO ${ }_{4}$ ) and hydrophobic behavior (PU/PM) which might have resulted in the improvement of the anticoagulant nature.

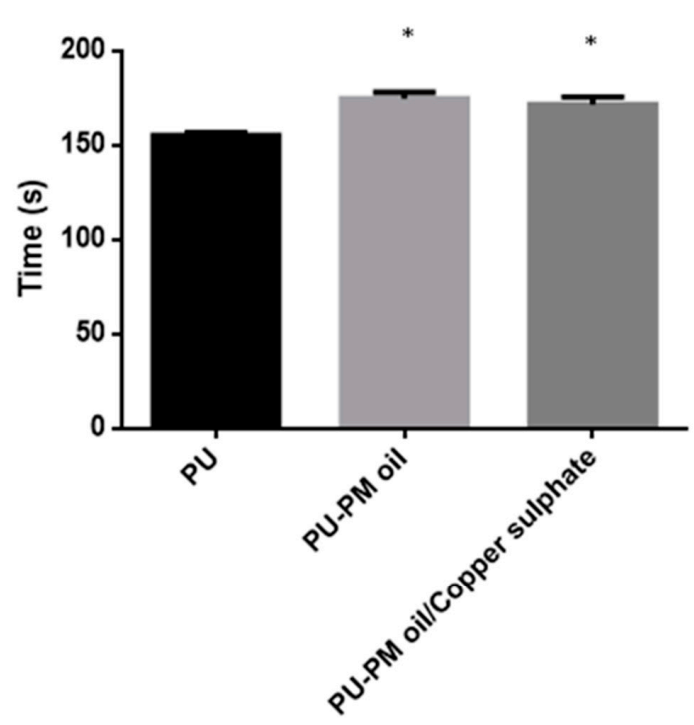

*mean differences were significant compared with pure PU $(p<0.05)$

Figure 7. APTT assay of PU, PU/PM, and PU/PM/CuSO

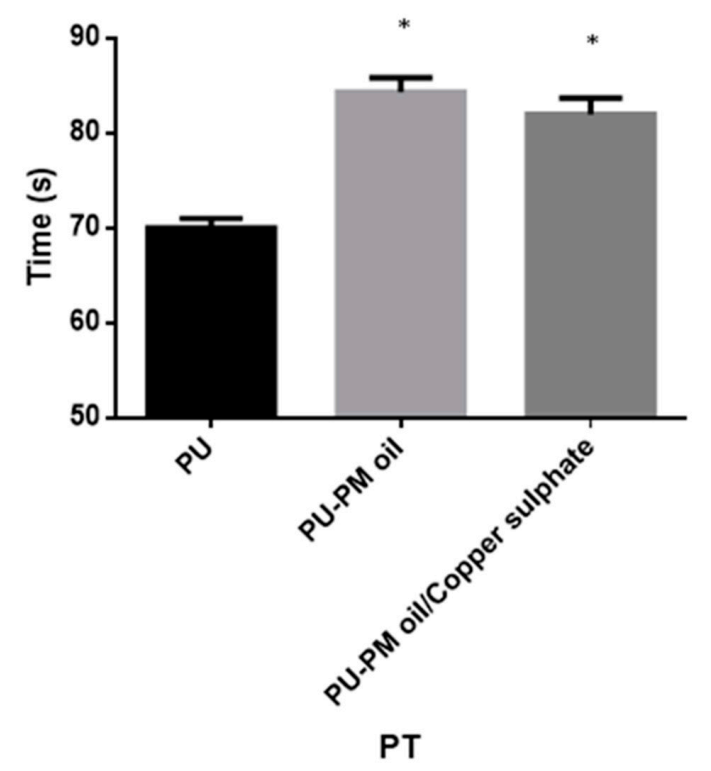

*mean differences were significant compared with pure PU $(p<0.05)$

Figure 8. $\mathrm{PT}$ assay $\mathrm{PU}, \mathrm{PU} / \mathrm{PM}$, and $\mathrm{PU} / \mathrm{PM} / \mathrm{CuSO}_{4}$. 


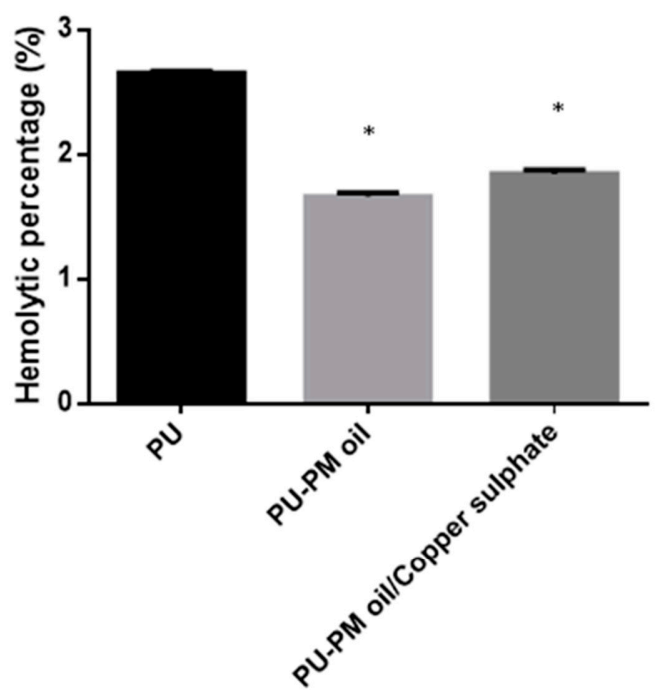

*mean differences were significant compared with pure $\mathrm{PU}(\mathrm{p}<0.05)$

Figure 9. Hemolytic assay PU, PU/PM, and PU/PM/CuSO

\subsection{Cytocompatibility Measurements}

Figure 10 presents the HDF cell viability in the electrospun membranes evaluated through MTS assay. After five days of cell culture, it was observed that the HDF cells were well adhered and proliferated in all electrospun membranes compared to the control plates. The cell viability percentage for the PU membrane was reported to be $130 \pm 4 \%$, while the electrospun PU/PM and $\mathrm{PU} / \mathrm{PM} / \mathrm{CuSO}_{4}$ composites showed cell viability of $133 \pm 11 \%$ and $144 \pm 3 \%$, respectively. Further, $\mathrm{HDF}$ cells viability in the electrospun $\mathrm{PU} / \mathrm{PM} / \mathrm{CuSO}_{4}$ composites was observed to be higher than the $\mathrm{PU} / \mathrm{PM}$ composites. As reported in the introduction section, $\mathrm{PM}$ oil contains polyphenols as one of their bioactive constituents. It has been reported that the phenolic components help in protecting the fibroblast cells against oxidative stress caused by hydrogen peroxide resulting in cell proliferation and migration. The phenolic compounds present in the PM oil might have influenced cell viability [40]. The reason for the improved HDF cell viability was perhaps due to their smaller fiber diameter (PU/PM) and hydrophilic behavior (PU/PM/ $\left.\mathrm{CuSO}_{4}\right)$ [41,42]. Hence, the improved cellular response of the developed composites might be suitable for wound dressing applications.

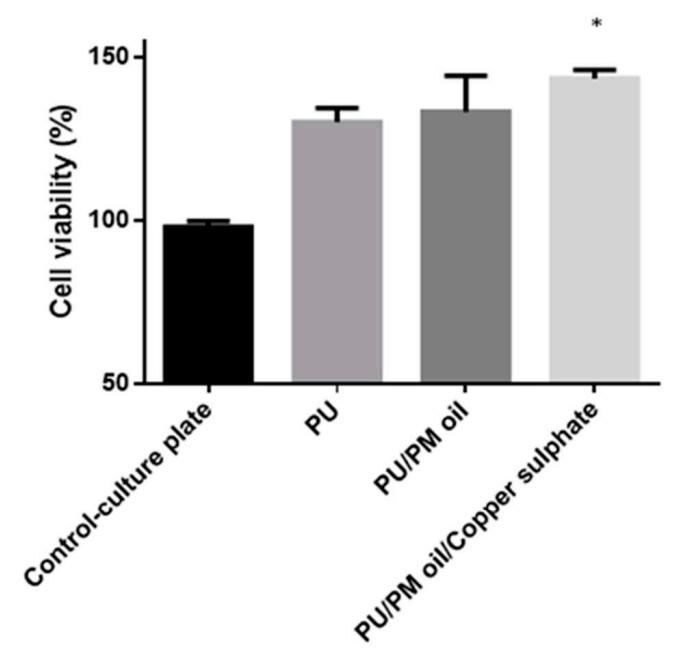

* mean differences were significant compared with pure $\mathrm{PU}(\mathrm{p}<0.05)$

Figure 10. MTS assay PU, PU/PM, and PU/PM/CuSO 4 . 


\section{Conclusion}

This work successfully evaluated the physicochemical and biocompatibility properties of electrospun composites based on polyurethane (PU) added with pepper mint (PM) oil and copper sulphate $\left(\mathrm{CuSO}_{4}\right)$. The fabricated composites showed improved physicochemcial properties compared to the pristine PU. Blood compatibility studies showed improved anti-coagulation time and less toxic behavior for the developed composites than the pristine PU. Finally, the cell viability of the fabricated composite was higher than the pristine PU as indicated in MTS assay. Hence, the fabricated wound dressing composite based on $\mathrm{PU} / \mathrm{PM}$ and $\mathrm{PU} / \mathrm{PM} / \mathrm{CuSO}_{4}$ rendering better physicochemical and biocompatible nature, mark its suitability for wound healing applications. In the future, it would be interesting to explore the cell proliferation and morphology characteristics of HDF cells using SEM analysis at different time points, which will further validate the claims of cytotoxicity.

Author Contributions: Conceptualization: S.K.J. and A.Z.M.K.; Methodology: S.K.J., M.P.M., A.Z.M.K.; Software: S.K.J. and M.P.M.; Validation: S.K.J., M.P.M., A.Z.M.K.; Formal Analysis: S.K.J. and A.Z.M.K.; Investigation: S.K.J., M.P.M., A.Z.M.K.; Resources: S.K.J. and A.Z.M.K.; Data Curation: S.K.J., M.P.M., A.Z.M.K.; Writing-Original Draft Preparation: M.P.M.; Writing-Review \& Editing: S.K.J., M.P.M. and A.Z.M.K.; Visualization: S.K.J. and A.Z.M.K.; Supervision: S.K.J. and A.Z.M.K.; Project Administration: S.K.J. and A.Z.M.K.; Funding Acquisition: A.Z.M.K. and S.K.J.

Funding: This project was majorly supported by MRUN funding with the Grant reference no. PY/2015/05186. This work was also partly supported by the Ministry of Higher Education Malaysia with the Grant no. Q.J130000.2545.17H00 and Q.J130000.2545.20H00.

Acknowledgments: Authors acknowledge the support of UPMU technical service.

Conflicts of Interest: The authors declare no conflict of interest.

\section{References}

1. Li, X.; Wang, C.; Yang, S.; Liu, P.; Zhang, B. Electrospun Pcl/mupirocin and chitosan/lidocaine hydrochloride multifunctional double layer nanofibrous scaffolds for wound dressing applications. Int. J. Nanomed. 2018, 13, 5287. [CrossRef] [PubMed]

2. Dhivya, S.; Padma, V.V.; Santhini, E. Wound dressings-A review. Bio Med. 2015, 5. [CrossRef] [PubMed]

3. Chen, X.; Zhao, R.; Wang, X.; Li, X.; Peng, F.; Jin, Z.; Gao, X.; Yu, J.; Wang, C. Electrospun mupirocin loaded polyurethane fiber mats for anti-infection burn wound dressing application. J. Biomater. Sci. Polym. 2017, 28, $162-176$. [CrossRef] [PubMed]

4. Yildirimer, L.; Thanh, N.T.; Seifalian, A.M. Skin regeneration scaffolds: A multimodal bottom-up approach. Trends Biotechnol. 2012, 30, 638-648. [CrossRef]

5. Fu, K.; Lu, Y.; Dirican, M.; Chen, C.; Yanilmaz, M.; Shi, Q.; Bradford, P.D.; Zhang, X. Chamber-confined silicon-carbon nanofiber composites for prolonged cycling life of Li-ion batteries. Nanoscale 2014, 6, 7489-7495. [CrossRef]

6. Wang, Y.; Zhang, X.; He, X.; Zhang, W.; Zhang, X.; Lu, C. In situ synthesis of $\mathrm{MnO}_{2}$ coated cellulose nanofibers hybrid for effective removal of methylene blue. Carbohydr. Polym. 2014, 110, 302-308. [CrossRef]

7. Lim, C.T. Nanofiber technology: Current status and emerging developments. Prog. Polym. Sci. 2017, 1, 70:1-70:7.

8. Rasouli, R.; Barhoum, A.; Bechelany, M.; Dufresne, A. Nanofibers for Biomedical and Healthcare Applications. Macromol. Biosci. 2018, 28, 1800256. [CrossRef]

9. Ali, I.H.; Khalil, I.A.; El-Sherbiny, I.M. Single-dose electrospun nanoparticles-in-nanofibers wound dressings with enhanced epithelialization; collagen deposition, and granulation Properties. ACS Appl. Mater. Interface 2016, 8, 14453-14469. [CrossRef] [PubMed]

10. Agarwal, S.; Wendorff, J.H.; Greiner, A. Use of electrospinning technique for biomedical applications. Polymer 2008, 49, 5603-5621. [CrossRef]

11. Rnjak-Kovacina, J.; Weiss, A.S. Increasing the pore size of electrospun scaffolds. Tissue Eng. Part B Rev. 2011, 17, 365-372. [CrossRef] [PubMed]

12. Tang, X.; Si, N.; Xu, L.; Liu, H. Effect of flow rate on diameter of electrospun nanoporous fibers. Therm. Sci. 2014, 18, 1447-1449. [CrossRef]

13. Zhang, C.; Yuan, X.; Wu, L.; Han, Y.; Sheng, J. Study on morphology of electrospun poly (vinyl alcohol) mats. Eur. Polym. J. 2005, 41, 423-432. [CrossRef] 
14. Yuan, X.; Zhang, Y.; Dong, C.; Sheng, J. Morphology of ultrafine polysulfone fibers prepared by electrospinning. Polym. Int. 2004, 53, 1704-1710. [CrossRef]

15. Tarus, B.; Fadel, N.; Al-Oufy, A.; El-Messiry, M. Effect of polymer concentration on the morphology and mechanical characteristics of electrospun cellulose acetate and poly (vinyl chloride) nanofiber mats. Alex. Eng. J. 2016, 55, 2975-2984. [CrossRef]

16. Abrigo, M.; McArthur, S.L.; Kingshott, P. Electrospun nanofibers as dressings for chronic wound care: Advances, challenges, and future prospects. Macromol. Biosci. 2014, 14, 772-792. [CrossRef] [PubMed]

17. Tecoflex ${ }^{\mathrm{TM}}$ TPU - Lubrizol. Available online: https://www.lubrizol.com/Life-Sciences/products/Tecoflex-TPU (accessed on 13 March 2019).

18. Jaganathan, S.K.; Mani, M.P.; Palaniappan, S.K.; Rathanasamy, R. Fabrication and characterisation of nanofibrous polyurethane scaffold incorporated with corn and neem oil using single stage electrospinning technique for bone tissue engineering applications. J. Polym. Res. 2018, 25, 146. [CrossRef]

19. Detta, N.; Errico, C.; Dinucci, D.; Puppi, D.; Clarke, D.A.; Reilly, G.C.; Chiellini, F. Novel electrospun polyurethane/gelatin composite meshes for vascular grafts. J. Mater. Sci. Mater. Med. 2010, 21, 1761-1769. [CrossRef]

20. Unnithan, A.R.; Pichiah, P.T.; Gnanasekaran, G.; Seenivasan, K.; Barakat, N.A.; Cha, Y.S.; Jung, C.H.; Shanmugam, A.; Kim, H.Y. Emu oil-based electrospun nanofibrous scaffolds for wound skin tissue engineering. Colloids. Surf. A Phys. Eng. Asp. 2012, 415, 454-460. [CrossRef]

21. Chao, C.Y.; Mani, M.P.; Jaganathan, S.K. Engineering electrospun multicomponent polyurethane scaffolding platform comprising grapeseed oil and honey/propolis for bone tissue regeneration. PLoS ONE 2018, 13, e0205699. [CrossRef]

22. Singh, R.; Shushni, M.A.; Belkheir, A. Antibacterial and antioxidant activities of Mentha piperita L. Arab. J. Chem. 2015, 8, 322-328. [CrossRef]

23. Karuza, L.; Blazevic, N.; Soljic, Z. Isolation and structure of flavonoids from peppermint (Mentha piperita) leaves. Acta Pharm. 1996, 46, 315-320.

24. Shimada, K.; Fujikawa, K.; Yahara, K.; Nakamura, T. Antioxidative properties of xanthan on the autooxidation of soybean oil in cyclodextrin. J. Agric. Food Chem. 1992, 40, 945-948. [CrossRef]

25. Sokovic, M.D.; Vukojevic, J.; Marin, P.D.; Brkic, D.D.; Vajs, V.; van Griensven, L.J.L.D. Chemical composition of essential oils of Thymus and Mentha species and their antifungal activities. Molecules 2009, 14, 238-249. [CrossRef]

26. Grigore, A. Plant phenolic compounds as immunomodulatory agents. In Phenolic Compounds-Biological Activity; InTech: London, UK, 2017.

27. Zhang, Y.J.; Gan, R.Y.; Li, S.; Zhou, Y.; Li, A.N.; Xu, D.P.; Li, H.B. Antioxidant phytochemicals for the prevention and treatment of chronic diseases. Molecules 2015, 20, 21138-21156. [CrossRef] [PubMed]

28. Amna, T.; Hassan, M.S.; Yang, J.; Khil, M.S.; Song, K.D.; Oh, J.D.; Hwang, I. Virgin olive oil blended polyurethane micro/nanofibers ornamented with copper oxide nanocrystals for biomedical applications. Int. J. Nanomed. 2014, 9, 891. [CrossRef] [PubMed]

29. Jaganathan, S.K.; Mani, M.P. Electrospun polyurethane nanofibrous composite impregnated with metallic copper for wound-healing application. 3 Biotech 2018, 8, 327. [CrossRef] [PubMed]

30. Jaganathan, S.K.; Mani, M.P. Single-stage synthesis of electrospun polyurethane scaffold impregnated with zinc nitrate nanofibers for wound healing applications. J. Appl. Polym. Sci. 2019, 136, 46942. [CrossRef]

31. Kim, H.H.; Kim, M.J.; Ryu, S.J.; Ki, C.S.; Park, Y.H. Effect of fiber diameter on surface morphology, mechanical property, and cell behavior of electrospun poly ( $\varepsilon$-caprolactone) mat. Fibers Polym. 2016, 17, 1033-1042. [CrossRef]

32. Chou, S.H.; Don, T.M.; Lai, W.C.; Cheng, L.P. Formation of microporous poly (hydroxybutyric acid) membranes for culture of osteoblast and fibroblast. Polym. Adv. Technol. 2009, 20, 1082-1090.

33. Sharifi, F.; Irani, S.; Zandi, M.; Soleimani, M.; Atyabi, S.M. Comparative of fibroblast and osteoblast cells adhesion on surface modified nanofibrous substrates based on polycaprolactone. Prog. Biomater. 2016, 5, 213-222. [CrossRef]

34. Vernon, B. (Ed.) Injectable Biomaterials: Science and Applications; Elsevier: Amsterdam, the Netherlands, 24 January 2011.

35. Balaji, A.; Jaganathan, S.K.; Ismail, A.F.; Rajasekar, R. Fabrication and hemocompatibility assessment of novel polyurethane-based bio-nanofibrous dressing loaded with honey and carica papaya extract for the management of burn injuries. Int. J. Nanomed. 2016, 11, 4339. 
36. Huang, N.; Yang, P.; Leng, Y.X.; Chen, J.Y.; Sun, H.; Wang, J.; Wang, G.J.; Ding, P.D.; Xi, T.F.; Leng, Y. Hemocompatibility of titanium oxide films. Biomaterials 2003, 24, 2177-2187. [CrossRef]

37. Jaganathan, S.; Mani, M.; Ismail, A.; Ayyar, M. Manufacturing and characterization of novel electrospun composite comprising polyurethane and mustard oil scaffold with enhanced blood compatibility. Polymers 2017, 9, 163. [CrossRef]

38. Ayyar, M.; Mani, M.P.; Jaganathan, S.K.; Rathanasamy, R. Preparation, characterization and blood compatibility assessment of a novel electrospun nanocomposite comprising polyurethane and ayurvedic-indhulekha oil for tissue engineering applications. Biomed. Eng./Biomed. Tech. 2018, 63, 245-253. [CrossRef] [PubMed]

39. Jaganathan, S.K.; Mani, M.P.; Ayyar, M.; Supriyanto, E. Engineered electrospun polyurethane and castor oil nanocomposite scaffolds for cardiovascular applications. J. Mater. Sci. 2017, 52, 10673-10685. [CrossRef]

40. Pitz, H.D.; Pereira, A.; Blasius, M.B.; Voytena, A.P.; Affonso, R.C.; Fanan, S.; Trevisan, A.C.; Ribeiro-do-Valle, R.M.; Maraschin, M. In vitro evaluation of the antioxidant activity and wound healing properties of Jaboticaba (Plinia peruviana) fruit peel Hydroalcoholic extract. Oxidative Med. Cell. Longev. 2016, 2016. [CrossRef] [PubMed]

41. Tian, F.; Hosseinkhani, H.; Hosseinkhani, M.; Khademhosseini, A.; Yokoyama, Y.; Estrada, G.G.; Kobayashi, H. Quantitative analysis of cell adhesion on aligned micro-and nanofibers. J. Biomed. Mater. Res. Part A 2008, 84, 291-299. [CrossRef]

42. Nandakumar, V.; Suresh, G.; Chittaranjan, S.; Doble, M. Synthesis and Characterization of Hydrophilic High Glycolic Acid-Poly (DL-Lactic-co-Glycolic Acid)/Polycaprolactam/Polyvinyl Alcohol Blends and Their Biomedical Application as a Ureteral Material. Ind. Eng. Chem. Res. 2012, 52, 751-760. [CrossRef]

(C) 2019 by the authors. Licensee MDPI, Basel, Switzerland. This article is an open access article distributed under the terms and conditions of the Creative Commons Attribution (CC BY) license (http://creativecommons.org/licenses/by/4.0/). 